\title{
Louisiana tells Ebola doctors to stay away from tropical medicine conference
}

\author{
Michael McCarthy
}

Seattle

The state of Louisiana has ordered medical researchers and healthcare workers not to come to New Orleans for the upcoming annual meeting of the American Society of Tropical Medicine and Hygiene if they have recently been to Sierra Leone, Liberia, or Guinea or have had recent contact with someone with Ebola virus disease.

In a letter addressed to the conference delegates Kathy Kliebert, secretary of Louisiana's Department of Health and Hospitals, and Kevin Davis, director of the state governor's Office of Homeland Security and Emergency Preparedness, wrote, "Given that conference participants with a travel and exposure history for EVD [Ebola virus disease] are recommended not to participate in large group settings (such as this conference) or to utilize public transport, we see no utility in you traveling to New Orleans to simply be confined to your room."

Louisiana requires anyone who has been in the Ebola affected nations of west Africa or been in contact with someone with the virus to remain in self quarantine for 21 days, the incubation period for Ebola infection, after their last potential exposure.

Louisiana's measures are stricter than the guidelines of the US Centers for Disease Control, which recommend that possible contacts with "low risk" of exposure be actively monitored by public health officials by daily phone calls to check for fever or symptoms. For people who are at "some risk," such as those who cared for a patient with Ebola but wore adequate protective gear, the CDC recommends direct active monitoring consisting of daily visits by a public health official. In some cases, additional restrictions may be imposed on a case by case basis, depending on how "intense" the contact's exposure had been, the CDC guidelines say.

Alan Magill, president of the American Society of Tropical Medicine and Hygiene and director of the Malaria program at the Bill \& Melinda Gates Foundation, said that the society did not believe that quarantine was warranted for people who were at "no or exceedingly low" risk. He said, "We think the CDC guidance is accurate, like most scientists and public health professionals do, and that's what we would prefer to follow." In response to the Ebola crisis, the society had added special panels and symposiums to the conference, Magill said. "The whole point of having an annual meeting of a professional society like this is that it allows people from around the world to come together and share their learning and share their experiences," he said. Some of the members of those panels and those attending were now not going to be able to travel to the conference, he said.

The conference's organizers will be talking with their technical team to see whether some experts who could now not come to the conference would be able to give their presentations remotely, but there was little time to make such arrangements, said Magill, as the five day conference begins Sunday 2 November.

The Ebola sessions would be recorded, Magill said, and, although the technical aspects had yet to be worked out, he expected that the society would try to get the Ebola presentations on to its website (www.astmh.org) as quickly as possible, to be "available free of charge in order to get the information out as quickly as we can."

Access all of The BMSs content on the ongoing Ebola outbreak at thebmj.com/ebola.

Cite this as: BMJ 2014;349:g6584

๑ BMJ Publishing Group Ltd 2014 